\title{
Lipoprotein lipase deficiency due to long-term heparinization presenting as severe hypertriglyceridaemia
} in pregnancy

\author{
G.F. Watts ${ }^{1}$, J. Cameron ${ }^{2}$, A. Henderson ${ }^{3}$ and W. Richmond ${ }^{3}$ \\ ${ }^{1}$ Department of Endocrinology and Chemical Pathology, United Medical and Dental Schools of Guy's and \\ St Thomas' Hospitals, St Thomas' Hospital, London SE1 7EH; ${ }^{2}$ Clinical Biochemistry Department, \\ Severalls Hospital, Boxted Road, Colchester CO4 5HG; and ${ }^{3}$ Department of Chemical Pathology, \\ St Mary's Hospital, Praed Street, London W2 INY, UK.
}

\begin{abstract}
Summary: A case of severe hypertriglyceridaemia presenting in the third trimester of pregnancy in a woman on long-term heparin prophylaxis is described. The hypertriglyceridaemia was attributed to impaired clearance of triglyceride-rich lipoprotein particles secondary to heparin-induced reduction in the activity of the lipolytic enzyme, lipoprotein lipase.
\end{abstract}

\section{Introduction}

The use of low-dose heparin in the prophylaxis of thrombo-embolic disease is well established. Less well known is the effect of heparin on lipoprotein metabolism. An intravenous injection of heparin acutely lowers plasma triglyceride by liberating into the plasma the endothelial-bound lipolytic enzyme, lipoprotein lipase (LPL). ${ }^{1}$ On the other hand, it has been suggested that prolonged administration of heparin may impair triglyceride clearance owing to depletion of the tissue stores of LPL. ${ }^{2}$ This phenomenon has, however, not yet been demonstrated in vivo. The rise in plasma oestrogen concentration in pregnancy can also disturb the metabolism of triglyceride-rich lipoproteins and in patients with a primary deficiency in LPL often results in severe hyperchylomicronaemia and acute pancreatitis. $^{3}$ The following report describes the influence of chronic administration of heparin on triglyceride metabolism during and after pregnancy.

\section{Case report}

At 4 weeks gestation during her third pregnancy, a 40 year old woman accidently fell and fractured her right tibia and fibula, which were subsequently immobilized in plaster of Paris for 6 months. Three weeks after removal of the plaster she was admitted

Correspondence: G.F. Watts, B.Sc., D.M., M.R.C.P. Accepted: 1 August 1991 to hospital with dyspnoea, pleuritic chest pain and haemoptysis. The clinical diagnosis of pulmonary embolism was made and following full anticoagulation with intravenous heparin for 10 days, she was discharged on prophylactic heparin, 10,000 units subcutaneously twice daily.

At 30 weeks gestation a blood sample sent to the laboratory for routine oestriol estimation was found to be grossly lipaemic and she was referred to the lipid clinic, from where she was admitted to hospital for further investigation. The plasma concentrations of cholesterol and triglyceride were grossly elevated at $40.0 \mathrm{mmol} / 1$ and $160 \mathrm{mmol} / \mathrm{l}$, respectively; lipoprotein fractionation revealed excessive accumulation of chylomicrons and very low density lipoproteins (Frederickson type V phenotype). There were no xanthomata and the liver and spleen were not palpable. Her father had died from a stroke aged 52 years and her mother from cancer. Her only brother refused a blood test, but 2 teenage children were normolipidaemic. The blood pressure was normal $(110 / 70 \mathrm{mmHg})$ and there was no proteinuria. Fasting blood glucose, liver and thyroid function, and renal biochemistry were all within normal limits. Plasma heparin activity was $0.30 \mathrm{IU} / \mathrm{ml} 1 \mathrm{~h}$ pre-injection.

The heparin regimen was continued and after 10 days on a $25 \mathrm{~g}$ fat, $2000 \mathrm{kcal}$ diet the plasma concentration of triglyceride fell to $20 \mathrm{mmol} / \mathrm{l}$ (Figure 1). The LPL activity was then specifically measured in post-heparin plasma (40 units/kg given intravenously) after inactivation of hepatic lipase with sodium dodecyl sulphate ${ }^{4}$ : the plasma LPL activity was $0.2 \mu \mathrm{mol}$ of free fatty acids $/ \mathrm{ml} / \mathrm{h}$ 


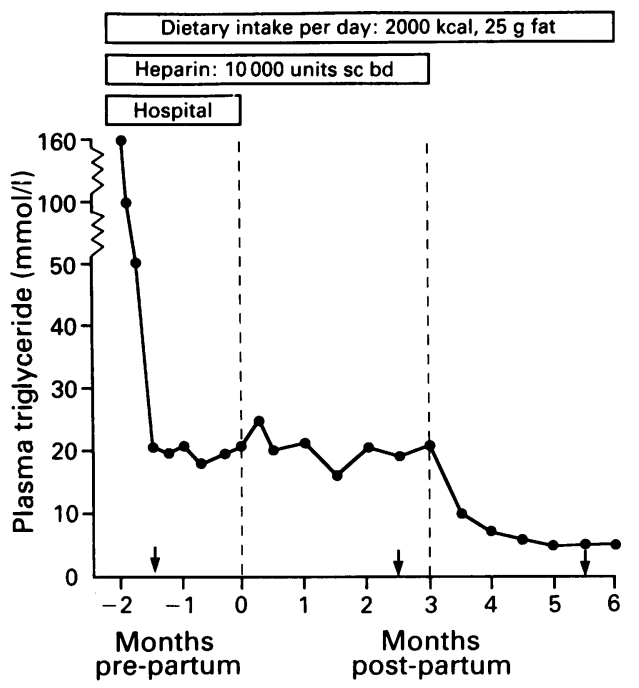

Figure 1 Plasma concentration of triglyceride in relation to pregnancy, heparin therapy and a low fat diet in a woman who presented with severe chylomicronaemia at 30 weeks gestation.

(reference range 4.9-17.5). The plasma fat removal capacity was also measured by an intravenous fat tolerance test ${ }^{5}$ : the disappearance rate $\left(\mathbf{K}_{2}\right)$ of a $10 \%$ emulsion of Intralipid $(1 \mathrm{ml} / \mathrm{kg})$ was $1.4 \% /$ min (reference range 4.2-11.2).

She remained asymptomatic for the rest of pregnancy and at 38 weeks gestation spontaneously gave birth to a $3 \mathrm{~kg}$, healthy boy; the plasma triglyceride concentration in cord blood was 0.14 $\mathrm{mmol} / \mathrm{l}$. She did not breast feed. She continued taking heparin 10,000 subcutaneously, twice daily until 3 months post-partum and a $25 \mathrm{~g}$ fat, 2000 $\mathrm{kcal}$ diet for a further 3 months. Whilst receiving heparin (plasma activity $0.28 \mathrm{IU} / \mathrm{ml} 1 \mathrm{~h}$ preinjection) the mean plasma concentration of triglyceride was $20 \mathrm{mmol} / \mathrm{l}$, but fell to less than 10 mmol/l after stopping heparin (Figure 1). LPL activity in post-heparin plasma and the $K_{2}$ of Intralipid were both suppressed 10 weeks postpartum, but became normal 10 weeks after heparin was discontinued (Figure 2); heparin-releasable hepatic lipase activity also showed similar changes, only reverting to normal $(15 \mu \mathrm{mol}$ of free fatty acids $/ \mathrm{ml} / \mathrm{h}$ ) after stopping heparin. A year later while on an isocaloric, fat-modified ( $66 \mathrm{~g}$ total fat) diet the plasma concentration of cholesterol and triglyceride remained slightly elevated at 7.0 $\mathrm{mmol} / 1$ and $3.5 \mathrm{mmol} / \mathrm{l}$, respectively.

\section{Discussion}

This case demonstrates for the first time that prolonged use of subcutaneous heparin may result

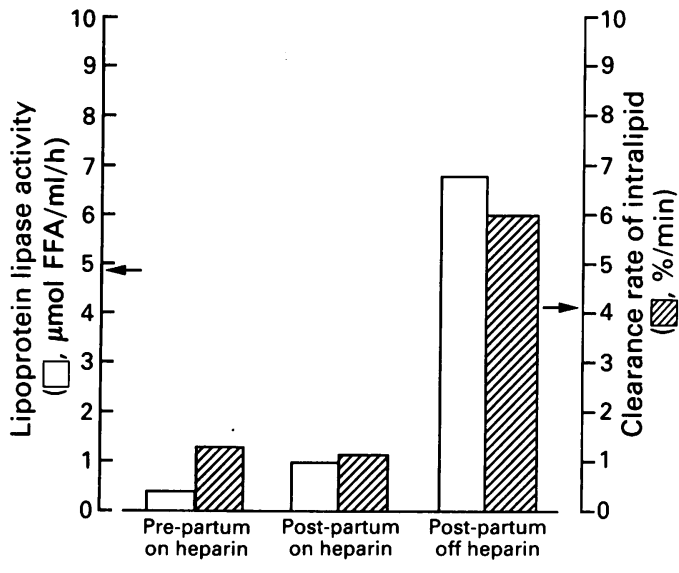

Figure 2 Plasma heparin-releasable lipoprotein lipase activity and clearance rate of Intralipid in relation to pregnancy and heparin therapy in the patient. FFA - free fatty acids. Arrows indicate lower limit of reference range.

in a profound disturbance of lipoprotein metabolism. We suggest that the mechanism for the decrease in clearance of triglyceride-rich lipoproteins is that long-term heparinization induced continuous release and subsequent degradation of LPL that exceeded the synthetic rate of the enzyme. This causal connection could have been tested further by re-challenging the patient with heparin 6 months post-partum, but the experiment was not considered ethical. Our findings are, however, consistent with other clinical observations showing that renal failure patients receiving haemodialysis and frequent heparinization often develop hypertriglyceridaemia ${ }^{2,6}$ and a reduced fractional catabolic rate of Intralipid. ${ }^{6}$ Continuous, intravenous heparin for 6 days has also been reported to reduce the clearance rate of Intralipid in non-renal failure patients. ${ }^{7}$ None of these studies, however, measured LPL activity.

That the fetus was healthy and of normal weight in the present report suggests that placental LPL may be more resistant to the effect of heparin than maternal LPL. Since our patient continued to exhibit mixed hyperlipidaemia with a post-heparin LPL activity at the lower end of the reference range after cessation of subcutaneous heparin, it is possible that she might have had familial combined hyperlipidaemia. ${ }^{8,9}$ This might have rendered her more susceptible to the effect of heparin on LPL activity. ${ }^{9}$ To confirm the diagnosis of familial combined hyperlipidaemia would have required a more extensive pedigree study. ${ }^{8}$

The pronounced chylomicronaemia at presentation was probably compounded by the oestrogenic response to pregnancy, since this increases hepatic secretion of very low density lipoproteins. ${ }^{10}$ The 
hormonal changes in pregnancy do not appear to influence LPL activity in humans, ${ }^{3,10,11}$ suggesting that our biochemical findings in this patient were primarily attributed to heparin and not to an effect of pregnancy. Oestrogens have, however, been shown to reduce LPL activity in adipose tissue of the rat. ${ }^{12}$

As in this report, severe chylomicronaemia in pregnancy may also be seen in patients with familial hypertriglyceridaemia ${ }^{13}$ or familial LPL deficiency, ${ }^{3,14}$ in whom acute pancreatitis has often been described. We emphasize that the risk of pancreatitis due to hyperchylomicronaemia in pregnancy may be mitigated by assiduous attention to diet alone. In this context it is noteworthy that a previously reported patient with familial LPL deficiency developed recurrent pancreatitis in pregnancy despite the apparent elimination of fat from the diet. ${ }^{3}$

\section{References}

1. Porte, D. \& Bierman, E.L. The effect of heparin infusion on plasma triglyceride in vivo and in vitro with a method for calculating triglyceride turnover. J Lab Clin Med 1969, 73: 631-648.

2. Bagdade, J.D., Porte, D. \& Bierman, E.L. Hypertriglyceridaemia: a metabolic consequence of chronic renal failure. New Engl J Med 1968, 269: 181-185.

3. Havel, R.J., Goldstein, J.L. \& Brown, M.S. Lipoproteins and lipid transport. In: Bondy, P.K. \& Rosenberg, L.E. (eds) Metabolic Control and Disease. Saunders, Philadelphia, 1980, pp. 393-494.

4. Baginsky, M.L. \& Brown, W.V. A new method for the measurement of lipoprotein lipase in post heparin plasma using sodium dodecyl sulphate for the inactivation of hepatic triglyceride lipase. J Lipid Res 1979, 20: 548-556.

5. Rossner, S. Studies on an intravenous fat tolerance test. Methodological, experimental and clinical experiences with Intralipid. Acta Med Scand 1974 (Suppl) 564: 7-24.

6. Chan, M.K., Varghese, Z., Persaud, J.W., Baillod, R.A. \& Moorhead, J.F. Fat clearance before and after heparin in chronic renal failure - haemodialysis reduces post-heparin fractional clearance rates of Intralipid. Clin Chim Acta 1980, 108: $95-101$.
From a practical viewpoint, we suggest that women receiving long-term heparin prophylaxis 3 during pregnancy should have their plasma lipids $\stackrel{\varnothing}{\varrho}$ quantified or, at least, the plasma from a fasting $C$. blood sample be visually examined for latescence. $\overrightarrow{\vec{F}}$ A plasma lipid screen prior to commencing treatment may also be useful in identifying those most susceptible to impairment of the clearance of $\frac{\bar{O}}{\bar{D}}$ triglyceride-rich lipoproteins. Should severe hyper- $\frac{\pi}{\overparen{ }}$ triglyceridaemia develop it may be controlled with a low fat diet without the need to discontinue of heparin.

\section{Acknowledgement}

We are grateful to $\mathrm{Mr} \mathrm{W}$. Jefferson for typing the manuscript.

7. Persson, E., Nordenstrom, J. \& Vinnars, E. Plasma clearance of fat emulsion during continuous heparin infusion. Acta Anaesthesiol Scand 1987, 31: 189-192.

8. Grundy, S.M., Chait, A. \& Brunzell, J.D. Familial combined hyperlipidaemia workshop. Arteriosclerosis 1987, 7: 203207.

9. Babirak, S.P., Iverius, P.H., Fujimoto, W.Y.\& Brunzell, J.Dீ Detection and characterisation of the heterozygote state fo lipoprotein lipase deficiency. Arteriosclerosis 1969, 9: 326 334.

10. Kissebah, A.H. \& Schectman, G. Hormones and lipoprotein metabolism. Clin Endocrinol Metab 1987, 3: 699-725.

11. Williams, C. \& Coltart, T.M. Adipose tissue metabolism in pregnancy. Br J Obstet Gynaecol 1978, 85: 43-46.

12. Tan, M.H., Sata, T. \& Havel, R.J. The significance of lipoprotein lipase in rat skeletal muscles. J Lipid Res 1977, 18: 363-370.

13. Glueck, C.J., Christopher, C., Mishkel, M.A., Tsang, R.C. \& Mellies, M.J. Pancreatitis, familial hypertriglyceridaemia and pregnancy. Am J Obstet Gynecol 1980, 136: 755-761.

14. Steiner, G., Myher, J.J. \& Kuksis, A. Milk and plasma lipid composition in a lactating patient with type I hyperlipoproteinaemia. Am J Clin Nutr 1985, 41: 121-128. 